\title{
Alterations in body composition and spasticity following subtetanic neuromuscular electrical stimulation training in spinal cord injury
}

\author{
Amanda Carty, BSc, MSc, PhD; ${ }^{1-2 *}$ Kirsty McCormack, BSc; ${ }^{1}$ Garret F. Coughlan, BSc, PhD ${ }^{1}$ Louis Crowe, \\ MB, BCh, BAO ; ${ }^{1}$ Brian Caulfield, BSc, MMedSci, PhD ${ }^{1}$ \\ ${ }^{1}$ Stim XDP Research Group, Institute for Sport and Health, University College Dublin, Dublin, Ireland; \\ ${ }^{2}$ Physiotherapy Department, National Rehabilitation Hospital, Dun Laoghaire, Dublin, Ireland
}

\begin{abstract}
The objective of this prospective cohort study was to investigate alterations in body composition variables and spasticity following subtetanic neuromuscular electrical stimulation (NMES) training in an adult population with spinal cord injury (SCI). Fourteen sedentary adults with SCI (thoracic [T]4-T11; American Spinal Injury Association Impairment Scale A/B; time since injury: $10.17+/-11.17 \mathrm{yr}$ ) were recruited from the National SCI database. Four adhesive electrodes $(175 \mathrm{~cm} 2$ each) were placed bilaterally on the proximal and distal quadriceps and hamstrings muscle groups and subtetanic contractions were elicited using a handheld NMES device. Lean body mass (LBM) and other body composition variables were measured using dual-energy X-ray absorptiometry. Spasticity was measured using the Spinal Cord Assessment Tool for Spastic Reflexes (SCATs) and visual analog scales. Verbal and written feedback was obtained to subjectively evaluate spasticity. LBM and spasticity measurements were taken before and after an 8 wk NMES training program in order to assess change. A statistically significant increase in lower-limb LBM, i.e., muscle tissue $(p>0.001)$, and a reduction in SCATs $(p<$ 0.001 ) score, indicating reduced spasticity, was observed. Subjective responses were positive. Improvements in body composition and SCATs scores indicate that subtetanic NMES training elicits favorable responses and may have important clinical implications for an SCI population.
\end{abstract}

Key words: body composition, electric stimulation, hypertrophy, intervention, lean body mass, lower limbs, muscle spasticity, spinal cord injuries, subtetanic, training.

\section{INTRODUCTION}

Skeletal muscle atrophy and the development of spasticity are two common sequelae of spinal cord injury (SCI). Skeletal muscle atrophy has been described as the most prominent adaptation [1] following SCI and is defined as the wasting away or decrease in the size of muscle [2]. This atrophy is rapid and severe and is reported to reach between 33 and 45 percent loss at $6 \mathrm{wk}$ following injury $[1,3]$, with continuing decline until a point of stable atrophy that is thought to occur approximately 9 to 12 mo post-SCI [4]. Loss of lean muscle mass is associated with metabolic alterations with significant cardiovascular health conditions, including decreased glucose tolerance, increased adipose to lean tissue ratio, hyperlipidemia, and increased prevalence of

\footnotetext{
Abbreviations: $\mathrm{BC}=$ body composition, $\mathrm{DXA}=$ dual-energy $\mathrm{X}$-ray absorptiometry, ES-RT = electrical stimulation resistance training, FES = functional electrical stimulation, LBM = lean body mass, $\mathrm{LCE}=$ leg cycling ergometry, $\mathrm{LL}=$ lower limb, NMES = neuromuscular electrical stimulation, $\mathrm{RBF}=$ regional body fat, SCATs $=$ Spinal Cord Assessment Tool for Spastic Reflexes, $\mathrm{SCI}=$ spinal cord injury, $\mathrm{TBF}=$ total body fat, $\mathrm{TM}=$ total mass, $\mathrm{VAS}=$ visual analog scale.

*Address all correspondence to Amanda Carty, MSc, PhD; Physiotherapy Department, National Rehabilitation Hospital, Rochestown Ave, Dun Laoghaire, Co. Dublin, Ireland. +00353-1 2355321. Email: amandacarty2@gmail.com http://dx.doi.org/10.1682/JRRD.2011.11.0220
} 
metabolic syndrome [5], and has been associated with fractures and deep vein thrombosis [4]. Because of the loss of protective cushioning, gluteal muscle atrophy has been clinically associated with pain in sitting and increased risk of pressure ulcer development [6].

Spasticity is another common consequence of SCI, with an incidence of 65 to 78 percent [7-8] in those with SCI for more than $1 \mathrm{yr}$. Spasticity in SCI has three distinct characteristics: (1) clonus and tendon hyperreflexia, (2) muscle hypertonia, and (3) flexor and extensor muscle spasms [9]. Clinically, it is well established that spasticity can be beneficial; however, spasticity may also have a negative effect on activities of daily living. Figures suggest that approximately 41 percent of those with spasticity report it as problematic [10], with one half to two thirds of participants requiring antispasmodic medication $[8,11]$.

Neuromuscular electrical stimulation (NMES) interventions for skeletal muscle atrophy and spasticity have typically employed electrical currents in the 30 to $70 \mathrm{~Hz}$ range to elicit tetanic contractions in target muscles in order to produce movement about a joint against an external load. The most common intervention of this type is functional electrical stimulation (FES) leg cycling ergometry (LCE), in which the external load is a cycle ergometer. Studies on FES-LCE have consistently demonstrated increased lean body mass (LBM) in the lower limbs (LLs) following a period of training [12-14], indicating a hypertrophic effect on muscle tissue. A less commonly observed NMES intervention for muscle atrophy and spasticity is electrical stimulation resistance training (ES-RT), in which the external load is dead weight resistance. Gorgey and Shepherd have recently demonstrated that this approach can increase muscle size in an SCI case study [5]. External loading, either by weighting the limb or through an ergometer, was considered a key element to these modalities to produce adequate stress and thereby muscle hypertrophy [15]. The response of spasticity to NMES has not been extensively investigated, but evidence from an FES-LCE training study indicates that it may reduce spasticity [16].

Despite the observed positive effects of FES-LCE and ES-RT, practical considerations limit their widespread use, leading to the need for more convenient therapies. These include extensive set-up time and cost. A recent report on a new NMES approach has demonstrated that repeated application of low-frequency currents to elicit subtetanic isometric contractions in leg muscles results in significant aerobic training effects in SCI [17-18]. This technique does not require the use of external apparatuses and therefore may be more convenient to use. Although designed for aerobic training, participant reports from pilot work suggested a longer-lasting effect on the muscles, including increased bulk and reduced spasticity. However, the effects of this technique on muscle spasticity and size have not been investigated to date.

Therefore, the objective of this investigation was to investigate alterations in body composition (BC) and spasticity following $8 \mathrm{wk}$ of training with the subtetanic NMES application. We hypothesized that this training program would result in (1) an increase in LL-LBM and (2) a reduction in spasticity in an untrained adult SCI population.

\section{METHODS}

Participants completed an 8 wk NMES training program. This comprised $1 \mathrm{~h} / \mathrm{d}, 5 \mathrm{~d} / \mathrm{wk}$ and was undertaken at home. Participants underwent BC and spasticity measurements prior to and following this 8 wk program in order to examine the changes from this training program. The study used a case-control repeated measures design.

\section{Participants and Recruitment}

We recruited 14 volunteer participants from the Spinal Injuries Ireland and National Rehabilitation Hospital databases. Participants attended the Human Performance Laboratory in University College Dublin for an NMES familiarization session (Table 1). They were provided with a participant information leaflet outlining the study and signed an informed consent form. Eleven male and three female adults with thoracic-level SCI, American Spinal Injury Association Impairment Scale A and B, and mean duration of injury of $10.17 \pm 11.7 \mathrm{yr}$ were enrolled. Exclusion criteria were those that would normally apply to NMES in addition to any cardiovascular/metabolic condition that precluded exercise, beta blockers, pelvic or LL metal implants, unhealed fractures or skin breakdown, and any other condition that could be affected by or affect the delivery of electrical stimulation.

\section{Neuromuscular Electrical Stimulation}

The NMES protocol used in this study was designed principally to elicit a pattern of LL muscle activity that would result in an aerobic exercise effect. An array of four adhesive hydrogel electrodes (each $17.5 \times 10.0 \mathrm{~cm}$ ) were placed bilaterally on the proximal and distal quadriceps 
Table 1.

Stimulation parameters.

\begin{tabular}{|c|c|c|c|c|c|c|c|}
\hline Phase & Duty Cycle & $\begin{array}{c}\text { Packet } \\
\text { Frequency } \\
(\mathbf{H z})\end{array}$ & $\begin{array}{l}\text { No. of Pulses } \\
\text { in Packet }\end{array}$ & $\begin{array}{c}\text { Internal } \\
\text { Frequency } \\
(\mathbf{H z})\end{array}$ & $\begin{array}{l}\text { Pulse Width } \\
(\mu s)\end{array}$ & $\begin{array}{c}\text { Phase } \\
\text { Duration } \\
\text { (min) }\end{array}$ & $\begin{array}{c}\text { Active } \\
\text { Electrodes } \\
\text { in Array }\end{array}$ \\
\hline$\overline{1}$ & Constant & 2 & 13 & $25-100$ & 1,000 & 14 & All \\
\hline 3 & Constant & 1 & 1 & 1 & 1,000 & 5 & Quads \\
\hline 4 & $\begin{array}{l}\text { Ramp-Up }=30 \mathrm{~s}, \\
\text { Contraction }=14 \mathrm{~s}, \\
\text { Ramp-Down }=30 \mathrm{~s} \text {, } \\
\text { Off }=5 \mathrm{~s}\end{array}$ & 2.5 & 10 & $20-100$ & 1,000 & 20 & All \\
\hline 5 & $\begin{array}{l}\text { Ramp-Up }=30 \mathrm{~s}, \\
\text { Contraction }=18 \mathrm{~s}, \\
\text { Ramp-Down }=90 \mathrm{~s}\end{array}$ & 2.5 & 10 & $20-100$ & 1,000 & 20 & All \\
\hline
\end{tabular}

and hamstrings muscle groups (Figure 1). Participants remained in their chair or transferred to a plinth to apply the electrodes, which were contained within a customized neoprene wrap (Figure 2). Subtetanic contractions in the quadriceps and hamstrings were elicited using a batterypowered muscle stimulator (NT2010, Biomedical Medical Research; Galway, Ireland). The stimulation protocol consisted of five separate phases over a total duration of $60 \mathrm{~min}$. In each phase, a series of pulse trains of mixed frequencies followed a range of pathways among electrodes in the array. These pathways were altered from pulse to pulse in order to produce multiple pathways for

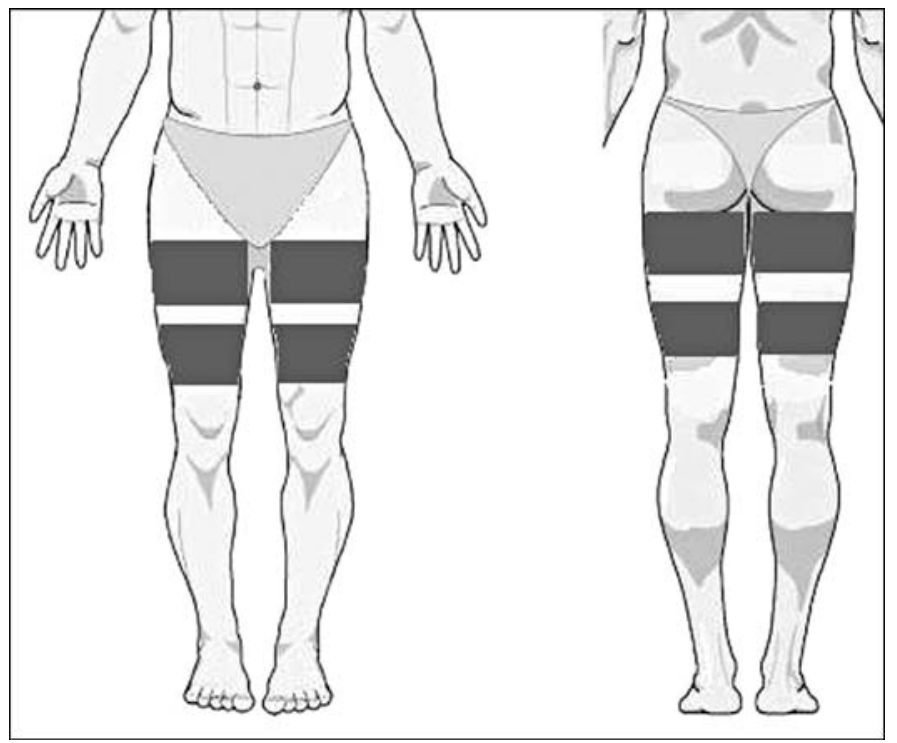

Figure 1.

Location of stimulating electrodes. current flow and therefore maximize motor recruitment. For example, one pulse might involve sending current from the proximal and distal quadriceps electrodes to the proximal hamstring electrode, while another might involve sending current from the proximal and distal hamstring electrodes to the distal quadriceps electrode. Our pilot testing had demonstrated that fatigue was a major limiting factor to tolerance of the protocol. Therefore, we

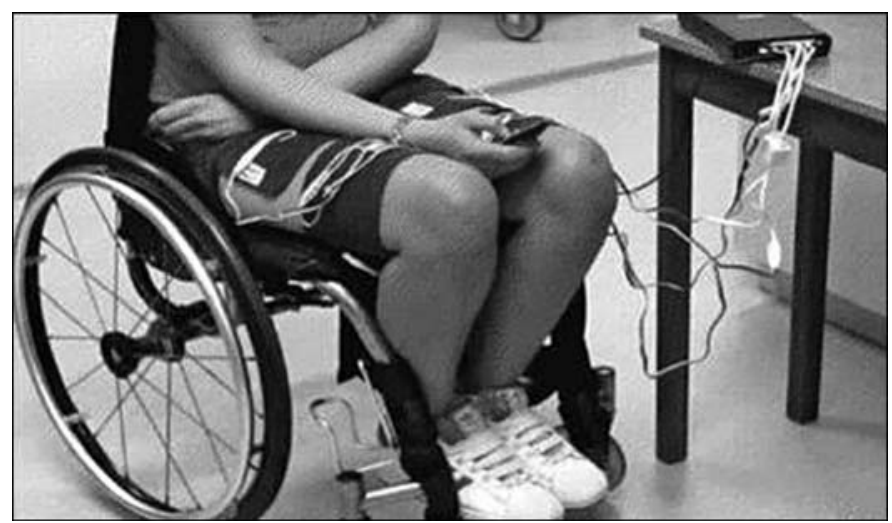

Figure 2.

Typical setup for neuromuscular electrical stimulation training session. Reprinted with permission from McCormack K, Carty A. The effects of a neuromuscular electrical stimulation training intervention on physiological measures in a spinal cord injured male: a case study. Physiother Ireland. 2011;31(2):30-35; and Carty A, McCormack K, Coughlan GF, Crowe L, Caulfield B. Increased aerobic fitness after neuromuscular electrical stimulation training in adults with spinal cord injury. Arch Phys Med Rehabil. 2012;93(5):790-95. 
employed a protocol with regular variations in packet frequency and pulse pathways as well as a period of relative rest and ramping elements to minimize the effect of fatigue and elicit rhythmical contractions in as many of the available muscle fibers as possible (Table 1). Phases 1 and 2 consisted mainly of consistent rhythmical contractions in hamstrings and quadriceps. Phase 3 represented a period of relatively low-intensity stimulation of the quadriceps muscles alone to afford a rest period and minimize fatigue. Phases 4 and 5 returned to rhythmical quadriceps and hamstring contractions with the addition of an element of ramping up and down (both phases) in intensity and a short rest period (phase 4), again to minimize fatigue.

Participants increased the intensity to their maximal tolerable intensity, with typical intensities being between 100 and $200 \mathrm{~mA}$. The maximum current amplitude available through the stimulator was $200 \mathrm{~mA}$.

\section{Training Protocol}

Participants trained for $8 \mathrm{wk}$ unsupervised at home for $1 \mathrm{~h} / \mathrm{d}, 5 \mathrm{~d} / \mathrm{wk}$ and were asked to maintain a training diary for the duration of the study, including weekly spasticity visual analog scale (VAS) scores.

\section{Data Measurement}

$\mathrm{BC}$ was measured via dual-energy X-ray absorptiometry (DXA) as per the standard whole-body analyses (Lunar DXA, GE Healthcare; Wilmington, Delaware). Variables evaluated were LL-LBM, total mass (TM), total body fat (TBF), regional body fat (RBF), and body mass index. Spasticity was evaluated using the Spinal Cord Assessment Tool for Spastic Reflexes (SCATs) [19]. This tool measures the severity of three distinct manifestations of spasticity in SCI: flexorspasm, extensorspasm, and clonus. The severity of each component is graded between 0 and 3 , giving a maximal spasticity score of 9 for each leg, or 18 for both legs as measured in this study. Participants were also asked to complete once weekly VASs during the training period. These scales asked the participant to "rate the severity/frequency of the severity of the spasticity you experienced during the last $24 \mathrm{~h}(0=$ none, $10=$ worst imaginable)" prior to the last training session of each week.

\section{Test Sessions}

Participants attended the laboratory for a familiarization session with the NMES. Control measurements were completed at this time, and participants went home for $2 \mathrm{wk}$ without training. Participants then returned to the laboratory for pretraining measurements. Correct application of the NMES was ensured at this session. Participants returned $8 \mathrm{wk}$ later for posttraining measurements. Conditions were standardized across all visits, i.e., same examiner for each participant, same test routine, empty bladder, and participants attended at the same time of day for each of the three visits to minimize the diurnal variation of spasticity.

\section{Data Analysis}

Differences in measured variables between each test session (Tables 2-3) were compared using repeated measures analysis of variance (Table 4). Post hoc $t$-tests were used to compare the differences between all measurement sessions (Table 5).

\section{RESULTS}

For all variables, there were no significant differences between control, testing, and pretraining measures (Table 5).

Significant differences were found between pretraining and posttraining for LL-LBM, TM, and RBF (Table 5). There was a tendency toward a reduction in TBF, but this difference did not reach statistical significance.

There was a significant decrease in SCATs score following the training period, indicating a reduction in measured spasticity. However, there were no significant differences in spasticity VAS scores as rated by the participants between any of the three test points (Table 5).

\section{DISCUSSION}

The principal finding of this study was that an $8 \mathrm{wk}$ training program with a subtetanic NMES protocol for the quadriceps and hamstrings resulted in a significant increase in LBM and a significant decrease in spasticity in a cohort of adults with SCI.

The mean increase in LL-LBM of 8.7 percent compares favorably with FES-LCE studies of similar duration, in which improvements of approximately 4 percent have been observed. The results of similar size FES-LCE training studies measured by DXA to date are presented in Table 6.

Sköld et al. demonstrated similar improvements using FES-LCE to those observed in the present study, but only after an intervention period of 6 mo [13]. The positive 
Table 2.

Group dual-energy X-ray absorptiometry results and within-subject effects.

\begin{tabular}{|c|c|c|c|c|c|c|c|c|c|c|c|c|c|c|c|}
\hline & \multicolumn{3}{|c|}{ LL-LBM (kg) } & \multirow[b]{2}{*}{ Baseline } & \multirow[b]{2}{*}{$\begin{array}{c}\text { Pre- } \\
\text { training }\end{array}$} & \multirow[b]{2}{*}{$\begin{array}{c}\text { Post- } \\
\text { training }\end{array}$} & \multirow[b]{2}{*}{ Baseline } & \multirow[b]{2}{*}{$\begin{array}{c}\text { Pre- } \\
\text { training }\end{array}$} & \multirow[b]{2}{*}{$\begin{array}{c}\text { Post- } \\
\text { training }\end{array}$} & \multirow[b]{2}{*}{ Baseline } & \multirow[b]{2}{*}{$\begin{array}{c}\text { Pre- } \\
\text { training }\end{array}$} & \multirow[b]{2}{*}{$\begin{array}{c}\text { Post- } \\
\text { training }\end{array}$} & \multirow[b]{2}{*}{ Baseline } & \multirow[b]{2}{*}{$\begin{array}{c}\text { Pre- } \\
\text { training }\end{array}$} & \multirow[b]{2}{*}{$\begin{array}{c}\text { Post- } \\
\text { training }\end{array}$} \\
\hline & Baseline & $\begin{array}{c}\text { Pre- } \\
\text { training }\end{array}$ & $\begin{array}{c}\text { Post- } \\
\text { training }\end{array}$ & & & & & & & & & & & & \\
\hline$\overline{1}$ & 8.7 & 8.5 & 8.6 & 50.5 & 49.3 & 51.7 & 28.3 & 23.5 & 27.8 & 21.9 & 21.1 & 22.7 & 22.5 & 22.7 & 22.7 \\
\hline 2 & 16.2 & 16.4 & 17.5 & 92.8 & 93 & 93.8 & 32.3 & 33.5 & 31.6 & 40.2 & 40 & 39 & 37.4 & 32 & 31.1 \\
\hline 3 & 11.2 & 11.4 & 11.6 & 57.2 & 58.6 & 58.6 & 32.7 & 31.9 & 31.3 & 26.2 & 25.2 & 25.3 & 18.4 & 21.5 & 21.5 \\
\hline 4 & 13.0 & 13.2 & 14.8 & 73.1 & 73.7 & 75.8 & 33.1 & 33.9 & 31 & 33.6 & 34.6 & 32.6 & 27.2 & 26 & 27 \\
\hline 5 & 17.3 & 17.1 & 16.5 & 83.5 & 83.3 & 80.6 & 26.6 & 26.6 & 27.4 & 32.2 & 31.8 & 31.7 & 27.3 & 28.6 & 26.3 \\
\hline 6 & 13.0 & 13.1 & 14.1 & 81.9 & 82.4 & 85.2 & 36.8 & 36.9 & 35.7 & 37.6 & 37.7 & 37.4 & 24.5 & 26.4 & 29.5 \\
\hline 7 & 11.5 & 11.3 & 12.5 & 61.2 & 61.9 & 63.1 & 39.1 & 39.5 & 38.6 & 34.7 & 35.4 & 32.5 & 26.2 & 24.2 & 24.6 \\
\hline 8 & 17.1 & 16.7 & 19.8 & 89.9 & 89 & 90.4 & 43.5 & 43.5 & 40.8 & 37.8 & 36 & 34.5 & 27 & 32.2 & 32.4 \\
\hline 9 & 13.9 & 14.1 & 15.5 & 66.4 & 66.9 & 69.8 & 24.1 & 25.1 & 26.8 & 22.2 & 22.5 & 27.3 & 23.4 & 20.7 & 20.9 \\
\hline 10 & 14.1 & 14.1 & 13.7 & 77.1 & 76.6 & 76.3 & 52 & 51 & 46.4 & 38.6 & 36.3 & 37.1 & 27.4 & 27.4 & 26.2 \\
\hline 11 & 11.0 & 10.6 & 12.7 & 66.5 & 66.7 & 69.9 & 31.2 & 28.1 & 25.3 & 41 & 40.6 & 40 & 23.8 & 23.8 & 25.1 \\
\hline 12 & 12.3 & 12.0 & 14.5 & 64.6 & 64.1 & 67.2 & 40.6 & 41.1 & 35.9 & 34.7 & 33.8 & 29.8 & 23.9 & 23.9 & 23.9 \\
\hline 13 & 19.5 & 19.2 & 20.8 & 91.9 & 93.9 & 95.2 & 27.7 & 28.4 & 26.4 & 33.9 & 34.4 & 33.2 & 26.1 & 30.0 & 30.0 \\
\hline 14 & 13.5 & 13.2 & 14.7 & 89.2 & 88.0 & 89.5 & 42.0 & 42.1 & 38.8 & 43.7 & 43.2 & 41.1 & 27.1 & 29.1 & 28.7 \\
\hline Mean & 13.7 & 13.6 & 14.8 & 74.7 & 74.8 & 76.2 & 35.0 & 34.7 & 33.1 & 34.2 & 33.8 & 33.2 & 25.9 & 26.3 & 26.4 \\
\hline SD & 2.9 & 2.9 & 3.2 & 13.9 & 13.9 & 13.5 & 7.8 & 8.1 & 6.4 & 6.7 & 6.6 & 5.5 & 4.2 & 3.7 & 3.6 \\
\hline
\end{tabular}

Table 3.

Group Spinal Cord Assessment Tool for Spastic Reflexes (SCATs) and visual analog scale (VAS) results (mean \pm standard deviation [SD]) and within-subject effects.

\begin{tabular}{|c|c|c|c|c|c|c|c|c|c|}
\hline & & AS Severi & & & & & & & \\
\hline & Baseline & $\begin{array}{c}\text { Pre- } \\
\text { training }\end{array}$ & $\begin{array}{c}\text { Post- } \\
\text { training }\end{array}$ & Baseline & $\begin{array}{c}\text { Pre- } \\
\text { training }\end{array}$ & $\begin{array}{c}\text { Post- } \\
\text { training }\end{array}$ & Baseline & $\begin{array}{c}\text { Pre- } \\
\text { training }\end{array}$ & $\begin{array}{c}\text { Post- } \\
\text { training }\end{array}$ \\
\hline$\overline{1}$ & 32 & 25 & 22 & 19 & 19 & 19 & 13 & 13 & 6 \\
\hline 2 & 60 & 55 & 49 & 63 & 83 & 45 & 14 & 15 & 10 \\
\hline 3 & 42 & 62 & 11 & 29 & 67 & 5 & 14 & 14 & 5 \\
\hline 4 & 10 & 8 & 25 & 25 & 5 & 8 & 10 & 9 & 6 \\
\hline 5 & 67 & 51 & 49 & 54 & 51 & 46 & 14 & 14 & 10 \\
\hline 6 & 47 & 40 & 56 & 32 & 25 & 45 & 10 & 8 & 5 \\
\hline 7 & 10 & 8 & 34 & 12 & 9 & 28 & 10 & 10 & 7 \\
\hline 8 & 53 & 41 & 34 & 38 & 56 & 28 & 8 & 8 & 3 \\
\hline 9 & 33 & 75 & 78 & 70 & 79 & 84 & 7 & 7 & 3 \\
\hline 10 & 30 & 37 & 37 & 41 & 57 & 42 & 11 & 9 & 5 \\
\hline 11 & 50 & 59 & 64 & 47 & 56 & 66 & 5 & 9 & 4 \\
\hline 12 & 14 & 26 & 7 & 11 & 5 & 8 & 10 & 11 & 7 \\
\hline 13 & 16 & 19 & 4 & 4 & 16 & 6 & 10 & 10 & 5 \\
\hline 14 & 4 & 2 & 1 & 4 & 4 & 1 & 8 & 9 & 6 \\
\hline Mean & 33.9 & 35.3 & 33.5 & 32.7 & 36.9 & 30.3 & 9.7 & 10.1 & 5.7 \\
\hline SD & 19.8 & 22.0 & 22.8 & 20.6 & 28.3 & 24.3 & 3.6 & 2.7 & 2.1 \\
\hline
\end{tabular}

result observed here may be due to a greater amount of muscle fiber being recruited through the larger electrodes. The total surface area of electrodes in this study was $700 \mathrm{~cm}^{2}\left(175 \mathrm{~cm}^{2} \times 4\right)$ per leg, and although not described in their study [13], the typical electrode size for FES-LCE systems is approximately $270 \mathrm{~cm}^{2}(5 \times 9 \mathrm{~cm}=$
$45 \mathrm{~cm}^{2} \times 6$ ) per leg. However, muscle recruitment was not directly measured so this cannot be confirmed from the present set of results. Also, although the electrodes were applied to the quadriceps and hamstring muscle groups, visible and palpable accessory contractions were achieved throughout abdominal, gluteal, and triceps surae 
JRRD, Volume 50, Number 2, 2013

Table 4.

Group dual-energy X-ray absorptiometry and Spinal Cord Assessment Tool for Spastic Reflexes (SCATs) results (mean \pm standard deviation) and within-subject effects.

\begin{tabular}{|c|c|c|c|c|c|c|}
\hline Measure & Baseline & $\begin{array}{l}\text { Pre- } \\
\text { training }\end{array}$ & $\begin{array}{l}\text { Post- } \\
\text { training }\end{array}$ & $\begin{array}{c}\text { Mean Difference } \\
\text { (pre- vs posttraining) }\end{array}$ & $\begin{array}{c}\% \text { Change } \\
\text { (pre- vs posttraining) }\end{array}$ & $\begin{array}{c}\text { Within-Subject } \\
\text { Effect Level of } \\
\text { Significance }\end{array}$ \\
\hline$\overline{\mathrm{LL}-\mathrm{LBM}(\mathrm{kg})}$ & $13.72 \pm 2.93$ & $13.65 \pm 2.91$ & $14.80 \pm 3.18$ & 1.16 & 8.65 & $>0.001$ \\
\hline $\mathrm{RBF}(\%)$ & $35.00 \pm 7.75$ & $34.65 \pm 8.05$ & $33.13 \pm 6.38$ & 1.52 & -4.39 & 0.01 \\
\hline TBF (\%) & $34.16 \pm 6.68$ & $33.76 \pm 6.62$ & $33.16 \pm 5.54$ & 0.6 & -0.6 & 0.15 \\
\hline BMI $\left(\mathrm{kg} / \mathrm{m}^{2}\right)$ & $25.87 \pm 4.16$ & $26.32 \pm 3.71$ & $26.42 \pm 3.57$ & 0.1 & 0.38 & 0.69 \\
\hline VAS (Severity) & $33.93 \pm 19.75$ & $35.27 \pm 22.05$ & $33.47 \pm 22.77$ & 0.46 & 1.36 & 0.80 \\
\hline VAS (Frequency) & $32.67 \pm 20.67$ & $36.87 \pm 28.26$ & $30.33 \pm 24.25$ & 2.34 & 7.16 & 0.27 \\
\hline
\end{tabular}

Note: Level of significance calculated using repeated measures analysis of variance (sphericity assumed).

$\mathrm{BMI}=$ body mass index, $\mathrm{LL}-\mathrm{LBM}=$ lower-limb lean body mass, $\mathrm{RBF}=$ regional body fat, $\mathrm{TBF}=$ total body fat, $\mathrm{TM}=$ total mass, $\mathrm{VAS}=$ visual analog scale.

Table 5.

Post hoc comparison for dual-energy X-ray absorptiometry and Spinal Cord Assessment Tool for Spastic Reflexes (SCATs) results between three test sessions ( $p$-values).

\begin{tabular}{lccc}
\hline \multicolumn{1}{c}{ Measure } & $\begin{array}{c}\text { Baseline vs Pretraining } \\
\text { Measures }\end{array}$ & $\begin{array}{c}\text { Pretraining vs Posttraining } \\
\text { Measures }\end{array}$ & $\begin{array}{c}\text { Posttraining vs Baseline } \\
\text { Measures }\end{array}$ \\
\hline LL-LBM & 0.97 & 0.02 & 0.01 \\
RBF & 0.45 & 0.04 & 0.01 \\
TM & 0.66 & 0.01 & 0.01 \\
TBF & 0.12 & 0.31 & 0.12 \\
BMI & 0.56 & 0.77 & 0.53 \\
SCATs & $<0.28$ & $<0.001$ & $<0.001$ \\
VAS Frequency & 0.15 & 0.25 & 0.97 \\
VAS Severity & 0.48 & 0.60 & 0.72 \\
\hline
\end{tabular}

Note: Post hoc comparisons carried out using two-sided $t$-test.

$\mathrm{BMI}=$ body mass index, $\mathrm{LL}-\mathrm{LBM}=$ lower-limb lean body mass, $\mathrm{RBF}=$ regional body fat, $\mathrm{TBF}=$ total body fat, $\mathrm{TM}=$ total mass, $\mathrm{VAS}=$ visual analog scale.

Table 6.

Mean percentage improvement in lower-limb lean body mass (LL-LBM) from functional electrical stimulation studies investigating lean body mass via dual-energy X-ray absorptiometry (DXA).

\begin{tabular}{lcccc}
\hline \multicolumn{1}{c}{ Study } & \multicolumn{1}{c}{$\boldsymbol{N}$} & \multicolumn{1}{c}{ Protocol } & Measurement & Mean \% LL-LBM Increase \\
\hline Griffin et al., 2009 [12] & 18 & $30 \mathrm{~min} \times 2-3 / \mathrm{wk}$ for $10 \mathrm{wk}$ & DXA & 4 \\
Sköld et al., 2002 [13] & $8($ from 15) & $30 \mathrm{~min} \times 3 / \mathrm{wk}$ for 6 mo & DXA & 10 \\
Hjeltnes et al., 1997 [14] & 5 & $30 \mathrm{~min} \times 7 /$ wk for $8 \mathrm{wk}$ & DXA & 4.3 \\
\hline \hline
\end{tabular}

groups. This may have been due to the pulse pathways involved in the stimulation protocol, which incorporated pulses traveling in multiple pathways, including from limb to limb (proximal quadriceps to proximal quadriceps and proximal hamstring to proximal hamstring). The observed increase in LL-LBM therefore challenges previous findings that electrical stimulation without external resistance is inadequate to produce muscle hypertrophy. However, the NMES protocol used in this study was primarily designed to increase aerobic fitness, i.e., low fre- quency, and the lack of resistance training may pose a limitation to the reversal of muscle atrophy toward normal parameters as demonstrated in previous NMES studies of differing protocols [20].

It has been suggested that an increase in intramuscular fat is responsible for some of the loss of muscle strength seen in the early stages post-SCI and that it is possible to reduce this fat percentage through NMES training [5]. The current results of both increased muscle mass and reduced regional percentage fat are promising, 
but more discrete measurement systems such as muscle biopsy would help to isolate the location of this fat loss, i.e., subcutaneous or intramuscular.

Several participants reported a temporary reduction in spasticity immediately after the training sessions. Participants were asked to complete spasticity VAS scores after the last training session of each week, but these scores were too incomplete to provide information as to any consistent perceived effect of the NMES on spasticity. It is possible that a more sensitive subjective scale (e.g., patient-reported effect of spasticity measure [20], Penn Spasm Frequency Scale [21]), coupled with greater compliance in the completion of the score, may more accurately illustrate the picture of spasticity posttraining. These reported temporary reductions in spasticity did not persist to demonstrate change in spasticity VAS scores at the test sessions.

The attempts to quantify spasticity in this study yielded mixed results, with the VAS from the test sessions showing no significant change in either direction, while the SCATs demonstrated a highly significant 44 percent reduction in score. Although both subjective and objective measures were used to evaluate spasticity, the mixed results further underpin the difficulty in measuring this complex phenomenon.

\section{FUTURE STUDIES}

This study did not address long-term training or analysis of outcomes, and this is an appropriate area for future studies in order to further explore the comparison with the existing evidence. A longer-term study would also allow for the examination of the extent of the further reversal of muscle atrophy.

Some investigators have examined the use of electrical stimulation in the early stages post-SCI and reported this modality's potential to prevent atrophy $[4,22]$ through isometric and isotonic NMES protocols. An appropriate area for future study would be whether the current NMES system delivering subtetanic contractions could prevent muscle atrophy in the acute stages postinjury. This maintenance of muscle bulk and composition may reduce the effect of muscle weakness as a primary impairment in the rehabilitation phase. It may promote maintenance of strength and a more desirable $\mathrm{BC}$ and therefore a more favorable metabolic profile, with the subsequent health benefits as laid out by Gorgey and Shepherd [5]. However, we have not directly measured the effect of training on strength or metabolic profile in this study and this should be addressed in future studies.

\section{CONCLUSIONS}

In conclusion, high intensity training with this novel NMES system resulted in improved BC and spasticity in an adult SCI population. These results reinforce the evidence for the reversibility of skeletal muscle atrophy in paralyzed muscle and improvement in $\mathrm{BC}$ with electrical stimulation training. This may provide for significant health, physical, and functional benefits at all rehabilitation phases following SCI. As many individuals with SCI await the arrival of stem cell technology and other rehabilitation technology such as implantable FES, this system appears to provide a convenient means of maintaining LL muscle size and composition.

\section{ACKNOWLEDGMENTS}

\section{Author Contributions:}

Study concept and design: A. Carty, B. Caulfield, L. Crowe. Acquisition of data: A. Carty, K. McCormack, G. F. Coughlan. Analysis and interpretation of data: A. Carty.

Drafting of manuscript: A. Carty.

Critical revision of manuscript for important intellectual content:

B. Caulfield.

Statistical analysis: A. Carty.

Obtained funding: B. Caulfield.

Administrative, technical, or material support: G. F. Coughlan.

Study supervision: B. Caulfield.

Financial Disclosures: Dr. Crowe is a stockholder in Biomedical Research Ltd. Dr. Crowe, Ms. Carty, Ms. McCormack, and Dr. Coughlan's work was supported by a grant that was partially funded by Biomedical Research Ltd. Biomedical Research Ltd. is the manufacturer of the stimulator used in this research. Dr. Caulfield declares no potential conflict of interest.

Funding/Support: This research was supported by Enterprise Ireland and Biomedical Research Ltd.

Additional Contributions: We would like to thank Spinal Injuries Ireland and the National Rehabilitation Hospital for assistance in recruiting participants. Also, thanks to the participants who gave their time for this study.

Institutional Review: This study received ethical approval from the Human Research Ethics Committee of University College Dublin and the Ethics Committee of the National Rehabilitation Hospital, Co. Dublin. All participants provided written informed consent.

Participant Follow-Up: The authors plan to inform participants of the publication of this study. 


\section{REFERENCES}

1. Gorgey AS, Dudley GA. Skeletal muscle atrophy and increased intramuscular fat after incomplete spinal cord injury. Spinal Cord. 2007;45(4):304-9. [PMID:16940987]

2. Wilmore J, Costill D, Kenney W. Physiology of sport and exercise. 4th ed. Champaign (IL): Human Kinetics; 2008 p. 310.

3. Castro MJ, Apple DF Jr, Hillegass EA, Dudley GA. Influence of complete spinal cord injury on skeletal muscle cross-sectional area within the first 6 months of injury. Eur J Appl Physiol. 1999;80(4):373-78. [PMID:10483809] http://dx.doi.org/10.1007/s004210050606

4. Baldi JC, Jackson RD, Moraille R, Mysiw WJ. Muscle atrophy is prevented in patients with acute spinal cord injury using functional electrical stimulation. Spinal Cord. 1998; 36(7):463-69. [PMID:9670381] http://dx.doi.org/10.1038/sj.sc.3100679

5. Gorgey AS, Shepherd C. Skeletal muscle hypertrophy and decreased intramuscular fat after unilateral resistance training in spinal cord injury: case report. J Spinal Cord Med. 2010;33(1):90-95. [PMID:20397451]

6. Bogie KM, Wang X, Triolo RJ. Long-term prevention of pressure ulcers in high-risk patients: a single case study of the use of gluteal neuromuscular electric stimulation. Arch Phys Med Rehabil. 2006;87(4):585-91. [PMID:16571402] http://dx.doi.org/10.1016/j.apmr.2005.11.020

7. Sköld C, Levi R, Seiger A. Spasticity after traumatic spinal cord injury: nature, severity, and location. Arch Phys Med Rehabil. 1999;80(12):1548-57. [PMID:10597805] http://dx.doi.org/10.1016/S0003-9993(99)90329-5

8. Maynard FM, Karunas RS, Waring WP 3rd. Epidemiology of spasticity following traumatic spinal cord injury. Arch Phys Med Rehabil. 1990;71(8):566-69. [PMID:2369291]

9. Adams MM, Hicks AL. Spasticity after spinal cord injury. Spinal Cord. 2005;43(10):577-86. [PMID:15838527] http://dx.doi.org/10.1038/sj.sc.3101757

10. Levi R, Hultling C, Nash MS, Seiger A. The Stockholm spinal cord injury study: 1 . Medical problems in a regional SCI population. Paraplegia. 1995;33(6):308-15. [PMID:7644255] http://dx.doi.org/10.1038/sc.1995.70

11. Sköld C. Spasticity in spinal cord injury: self- and clinically rated intrinsic fluctuations and intervention-induced changes. Arch Phys Med Rehabil. 2000;81(2):144-49. [PMID:10668766] http://dx.doi.org/10.1016/S0003-9993(00)90132-1

12. Griffin L, Decker MJ, Hwang JY, Wang B, Kitchen K, Ding Z, Ivy JL. Functional electrical stimulation cycling improves body composition, metabolic and neural factors in persons with spinal cord injury. J Electromyogr Kinesiol. 2009;19(4):614-22. [PMID:18440241] http://dx.doi.org/10.1016/j.jelekin.2008.03.002
13. Sköld C, Lönn L, Harms-Ringdahl K, Hultling C, Levi R, Nash M, Seiger A. Effects of functional electrical stimulation training for six months on body composition and spasticity in motor complete tetraplegic spinal cord-injured individuals. J Rehabil Med. 2002;34(1):25-32.

[PMID:11900259]

http://dx.doi.org/10.1080/165019702317242677

14. Hjeltnes N, Aksnes AK, Birkeland KI, Johansen J, Lannem A, Wallberg-Henriksson H. Improved body composition after $8 \mathrm{wk}$ of electrically stimulated leg cycling in tetraplegic patients. Am J Physiol. 1997;273(3 Pt 2):R1072-79. [PMID:9321888]

15. Martin TP, Stein RB, Hoeppner PH, Reid DC. Influence of electrical stimulation on the morphological and metabolic properties of paralyzed muscle. J Appl Physiol. 1992; 72(4):1401-6. [PMID:1534322]

16. Ragnarsson KT. Functional electrical stimulation and suppression of spasticity following spinal cord injury. Bull N Y Acad Med. 1992;68(2):351-64. [PMID:1586870]

17. Caulfield B, Crowe L, Minogue C, Bannerjee P, Clark A. The use of electrical stimulation to elicit a cardiovascular exercise response without joint loading: A case study. J Exerc Physiol. 2004;7:84-88.

18. McCormack K, Carty A, Coughlan G, Crowe L, Caulfield B. The effects of a neuromuscular electrical stimulation training intervention on physiological measures in a spinal cord injured population. Physiother Ireland. 2010;31:30-35.

19. Benz EN, Hornby TG, Bode RK, Scheidt RA, Schmit BD. A physiologically based clinical measure for spastic reflexes in spinal cord injury. Arch Phys Med Rehabil. 2005;86(1):52-59. [PMID:15640989] http://dx.doi.org/10.1016/j.apmr.2004.01.033

20. Taylor PN, Ewins DJ, Fox B, Grundy D, Swain ID. Limb blood flow, cardiac output and quadriceps muscle bulk following spinal cord injury and the effect of training for the Odstock functional electrical stimulation standing system. Paraplegia. 1993;31(5):303-10. [PMID:8332376] http://dx.doi.org/10.1038/sc.1993.54

21. Cook KF, Teal CR, Engebretson JC, Hart KA, Mahoney JS, Robinson-Whelen S, Sherwood AM. Development and validation of the patient Reported Impact of Spasticity Measure (PRISM). J Rehabil Res Dev. 2007;44(3):363-71. [PMID:18247233]

http://dx.doi.org/10.1682/JRRD.2006.04.0036

22. Hsieh JT, Wolfe DL, Miller WC, Curt A; SCIRE Research Team. Spasticity outcome measures in spinal cord injury: psychometric properties and clinical utilities. Spinal Cord. 2008;46(2):86-95. [PMID:17909559] http://dx.doi.org/10.1038/sj.sc.3102125

Submitted for publication November 18, 2011. Accepted in revised form June 25, 2012. 
This article and any supplementary material should be cited as follows:

Carty A, McCormack K, Coughlan GF, Crowe L, Caulfield B. Alterations in body composition and spasticity following subtetanic neuromuscular electrical stimulation training in spinal cord injury. J Rehabil Res Dev.
2013;50(2):193-202.

http://dx.doi.org/10.1682/JRRD.2011.11.0220

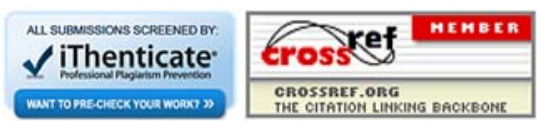


